TI 2018-094/VII

Tinbergen Institute Discussion Paper
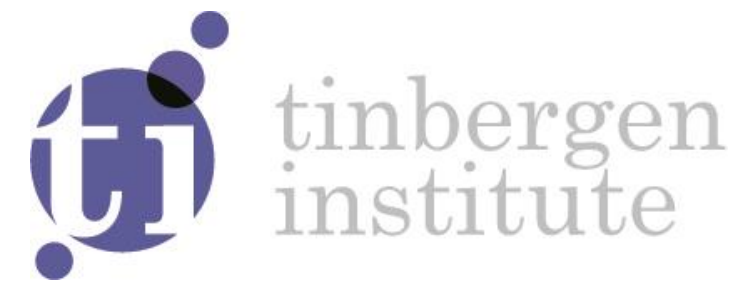

\title{
Non-Competitive Wage-Setting as a Cause of Unfriendly and Inefficient Leadership
}

Robert (A.J.) Dur ${ }^{1}$

Ola Kvaløy ${ }^{2}$

Anja Schöttner ${ }^{3}$

${ }^{1}$ Department of Economics, Erasmus University Rotterdam; CESifo Munich; IZA Bonn

2 University of Stavanger Business School; Norwegian School of Economics; CESifo Munich

${ }^{3}$ Humboldt-Universität zu Berlin 
Tinbergen Institute is the graduate school and research institute in economics of Erasmus University Rotterdam, the University of Amsterdam and VU University Amsterdam.

Contact: discussionpapers@tinbergen.nl

More TI discussion papers can be downloaded at http://www.tinbergen.nl

Tinbergen Institute has two locations:

Tinbergen Institute Amsterdam

Gustav Mahlerplein 117

1082 MS Amsterdam

The Netherlands

Tel.: +31(0)205984580

Tinbergen Institute Rotterdam

Burg. Oudlaan 50

3062 PA Rotterdam

The Netherlands

Tel.: +31(0)10408 8900 


\title{
Non-Competitive Wage-Setting as a Cause of Unfriendly and Inefficient Leadership
}

\author{
Robert Dur, Ola Kvaløy† and Anja Schöttner
}

This draft: November 2018

\begin{abstract}
This paper develops a simple economic model to examine how leadership styles in organizations depend on the prevailing wage-setting conditions for workers. In particular, we examine a leader who can - in addition to the use of monetary incentives - motivate a worker by adopting leadership styles that differ in their nonmonetary consequences for the worker's well-being. Some leadership styles produce non-monetary benefits for workers (such as those involving the provision of praise to high-performing workers), other styles impose non-monetary costs (such as those involving social punishment for low performers). We show that leaders never use the latter type of leadership when the worker is hired in a competitive labor market. In contrast, in labor markets with non-competitive wage-setting (e.g., in the presence of trade union bargaining or minimum wage legislation) leaders sometimes do use the 'unfriendly' style, and the more so the worse the worker's labor market prospects are. We show that this is socially inefficient. 'Friendly' leadership styles are always adopted when they are socially efficient.
\end{abstract}

JEL-Codes: M5.

Keywords: leadership styles, incentives, motivation, wage-setting.

${ }^{*}$ Erasmus University Rotterdam, Tinbergen Institute, CESifo Munich, and IZA Bonn. E-mail: dur@ese.eur.nl

${ }^{\dagger}$ University of Stavanger Business School, Norwegian School of Economics, and CESifo Munich. Email: ola.kvaloy@uis.no

${ }^{\ddagger}$ Humboldt-Universität zu Berlin. E-mail: anja.schoettner@hu-berlin.de 


\section{Introduction}

Leaders differ widely in the styles they adopt to motivate their workers. Some leaders use styles that, simultaneously, motivate workers as well as increase workers' job satisfaction. Think for instance of leaders who provide praise from time to time in a thoughtful manner. This likely makes workers feel better motivated and more satisfied with their job at the same time. However, evidence abounds that not all leaders act in this 'friendly' way. Some leaders try to keep workers motivated by harassing poor performers, hoping that this will impress the workforce at large and keep them from slacking down. Clearly, the use of such 'unfriendly' leadership styles will decrease rather than increase workers' well-being on the job.

This paper is concerned with the question of leaders' choice of style and, in particular, how this choice is affected by the labor market conditions workers face. We compare leaders who employ workers hired in a competitive labor market with leaders who face a binding minimum wage constraint when hiring workers. Such a wage constraint may arise for a variety of reasons including trade union wage bargaining, minimum wage legislation, and downward wage rigidity. We find that the presence of a wage constraint has major consequences for the use of the 'unfriendly' leadership style. While it is never used when workers are hired in a competitive labor market, the 'unfriendly' leadership style is sometimes used when wage-setting is non-competitive, and the more so the worse the workers' labor market prospects are. The intuition is that in competitive labor markets, leaders need to compensate workers for all of the costs imposed on them by using an 'unfriendly' leadership style. When leaders can also motivate workers using incentive pay, they will never use the 'unfriendly' leadership style, because it is always more costly to attain higher effort in this way than by increasing incentive pay. In contrast, when leaders need to meet a binding wage constraint, they sometimes do adopt the 'unfriendly' leadership style, and particularly so when workers' labor market prospects are bad. The reason is that in such labor markets, workers earn a rent when staying with their current employer, and hence need not be fully compensated for the harm imposed on them. This can make the 'unfriendly' leadership style an attractive alternative to incentive pay. The use of 'friendly' leadership styles is less responsive to wage-setting conditions, because the use of this style allows the leader to reduce total pay both in the presence and in the absence of a binding wage constraint. ${ }^{1}$

In addition to this positive analysis yielding the predictions just described, we also perform a welfare analysis. We find that whenever the friendly style is efficient from

\footnotetext{
${ }^{1}$ Clemens et al. (2018) have concurrently with the present study argued that a binding minimum wage may reduce fringe benefits provided by employers. We do not find such an effect for the friendly leadership style, because friendly leadership is a substitute for incentive pay in our framework, something which is absent in the model by Clemens et al. (2018).
} 
a social welfare perspective, it is adopted by the leader. The unfriendly style, on the other hand, is never efficient, and yet sometimes adopted when wage-setting is noncompetitive. The reason for leaders to adopt an inefficient style is that it allows them to extract part of the rents that would otherwise end up in the hands of the workers.

While the main part of our analysis considers a one-shot game and assumes commitment on the side of the leader, in the penultimate section we show that with repeated interaction between the leader and worker, the assumption of commitment is no longer needed. Indeed, our main results hold under self-enforcing contracts. Interestingly, while the self-enforcing condition for friendly leadership is independent of labor-market conditions, the condition for unfriendly leadership is not. If the worker's labor market prospects are rather bad, unfriendly leadership is more likely to be self-enforcing.

The paper is structured as follows. In the next section we discuss the related literature. Next, Section 3 describes our model. In Section 4 we analyze under which conditions the adoption of each leadership style is beneficial relative to pure monetary incentives, while in Section 5 we discuss the optimal choice between leadership styles. In Section 6 we study repeated interactions, and analyze under which conditions the leadership styles are self-enforcing. Finally, Section 7 concludes.

\section{Related literature}

Our paper contributes to a small, but growing literature using formal modelling to analyze leadership. Indeed, economists have extensively analyzed how leaders (or principals) can induce workers (or agents) to exert the right level or type of effort, but the dominant approach is contractual: Incentive problems are solved by contracts and/or organizational design. The leadership literature, on the other hand, has focused much less on contracts, but concentrates on how leaders can (in economic terms) influence the beliefs and/or preferences of the workers. As demonstrated in a recent survey by Zehnder et al. (2017), this part of leadership has been largely ignored by economists so far.

In our model the leader can take performance contingent actions ex post that praise or punish good or bad performance, resulting in additional non-monetary utility/disutility for the worker. This in contrast to motivational actions ex ante, which is the most common approach in the literature studying formally how leaders can motivate workers with words or actions. Dur et al. (2010) and Kvaløy and Schöttner (2015) consider models in which motivational actions reduces the effort costs of the worker, while Rotemberg and Saloner $(1993,1994,2000)$ consider in a series of papers how vision and leadership style can affect incentive contracts and workers' motivation. Van den Steen (2005) analyzes how managers with strong beliefs about the right course of action can attract workers with similar beliefs, while Hermalin (2017) analyzes how charismatic leaders with superior information can make emotional appeals that induce both 'emotional' workers and 
rational workers to work harder. ${ }^{2}$ Akerlof and Kranton $(2000,2005)$ study how the firm can take actions that transform the workers' identity, while Dur et al. (2010) analyze a model where the worker's marginal costs of effort are decreasing and the worker's wellbeing is increasing in the attention given by the leader. In contrast to all these papers, we consider performance contingent leadership actions that may also be harmful for the worker. Moreover, a distinguishing feature of our paper is that we investigate how the choice of these different leadership instruments depends on the prevailing labor market conditions for workers.

Our paper is also related to economic models of intrinsic motivation, such as Bénabou and Tirole (2003, 2006), Besley and Ghatak (2005), Delfgaauw and Dur (2007, 2008), and Ellingsen and Johannesson (2008) - see Besley and Ghatak (2018) and Cassar and Meier (2018) for recent surveys. Like these papers, we assume that workers obtain utility from work (or performances), but in contrast to their models, the non-monetary utilities in our model stem directly from costly leadership actions.

With respect to the (non-economic) leadership literature, our paper is related both to the literature on leadership emergence and leadership effectiveness (or leadership style). The literature on leadership emergence has mainly focused on the psychological traits of the individuals who emerge as leaders (see, e.g., Judge et al., 2002). We contribute to this literature by showing that economic and/or institutional conditions can determine the returns to and, hence, emergence of different leader personalities.

The huge literature on leadership style often evolves around the concepts of transformational and transactional leadership. While transactional leaders emphasize rewards in exchange for satisfying performance, transformational leaders inspire, persuade, and motivate their workers by articulating meaning, visions, and goals (see Bass, 1990, House and Aditya, 1997 and Robbins and Judge, 2013). In our set-up, the distinction between transformational and transactional leadership is less important. What is important is whether the leadership actions have positive or negative effects on the workers' wellbeing, i.e., whether the style is 'friendly' or 'unfriendly'. Leadership scholars refer to the unfriendly style as destructive (Ferris et al., 2007), abusive (Tepper, 2000), incivil (Pearson et al., 2000), and toxic (Lipman-Blumen, 2004). The literature mainly treats these leadership styles as harmful and less efficient. However, some recent papers also discuss how destructive leadership in some situations can promote organizational performance (Salin, 2003, and Ferris et al., 2007). This is also the case in our paper. Even if unfriendly leadership reduces the workers' well being, it sometimes improves the organization's performance. In this sense, the unfriendly leadership style we analyze is more associated with theory X leadership (McGregor, 1960) and what is later termed directive leadership (see House, 1971, and Pearce et al., 2003). This leadership style opens for

\footnotetext{
${ }^{2}$ There are several papers on the economics of leadership that emphasize the importance of information: The leader has followers because of superior skills or superior information about the right course of actions for the firm, see Hermalin (1998, 2007), Komai et al. (2007), Komai and Stegman (2010), and Lazear (2012).
} 
threats, punishments, and contingent reprimands in order to promote high performance (Pearce et al., 2003).

There seems to be a consensus in the literature that the task and job characteristics are crucial for the effectiveness of different leadership styles (see Zehnder et al., 2017). Our model can potentially account for this by letting leadership costs or non-monetary utilities be a function of task or job characteristics. However, there is also evidence that similar firms use very different management practises and leadership styles (Bloom et al., 2012, House et al., 2004, Artz et al., 2018). In line with this, Liu et al. (2003) argue - in a conceptual model - that employment modes and contracting relationships may matter more for the choice of leadership style than task and job characteristics. Our paper supports this conjecture by developing a novel argument using a formal model. The same task or job could meet very different leadership styles. It is mainly the wagesetting regime, and thus the nature of the labor market, rather than the nature of the task that determines optimal leadership style in our model.

Our model also challenges the prevailing (non-formal) theory on the relationship between leadership style and employee turnover. The standard hypothesis is that employees will want to quit their job if they are exposed to forms of unfriendly leadership, and hence that unfriendly - or destructive - leadership increases turnover (see Hyson, 2016, for a recent overview). We show that this theoretical relationship is not so straightforward. It is exactly when turnover rates are low - or more precisely, when the outside options are bad and workers earn a rent - that one may see unfriendly leadership. Interestingly, the empirical relationship between destructive leadership and employee turnover is not so clear, indicating that the mechanism we describe in our model may balance the "wanting to quit" motives.

\section{The model}

A leader needs to hire a worker to perform a task. The worker can choose between two effort levels, high and low. The worker's costs of high effort are $c>0$, while low effort does not entail any effort costs. Effort is non-observable. Output is verifiable and can be high or low, where expected output increases with effort. Specifically, when effort is low, output is high with probability $\alpha \geq 0$. When effort is high, output is high with probability $\alpha+\rho$, where $0<\rho$ and $\alpha+\rho<1$. We assume throughout that the leader always wants to induce the worker to choose high effort, because the increase in expected output always exceeds the increase in costs. Thus, our focus is not on whether, but on how the leader will motivate the worker.

In order to motivate the worker, the leader can use monetary incentives and/or implement certain leadership styles. The monetary incentive consists of a bonus $b$ paid to the worker when output is high. In addition to a possible bonus, the worker earns a base salary $w$. The leader can choose between two leadership styles, friendly (style $F$ ) and 
unfriendly (style $U$ ). Style $F$ provides non-monetary benefits $r$ to workers conditional on good performance, e.g. through provision of praise. Style $U$ imposes a non-monetary disutility on the worker of $s$ when output is low, e.g., through social punishment. If a leader takes an action (i.e., either to provide praise or to engage in social punishment), this entails costs $k_{i}>0$, where $i$ is either $F$ or $U$. We also assume that adopting a leadership style is never sufficient to induce high effort; i.e., the leader will always set a strictly positive bonus. As will become clear later on, this assumption amounts to $r, s<c / \rho$.

In practice, the provision of the type of non-monetary benefits or punishments that we have in mind are typically not expressed in explicit contracts. Like the worker's effort, the leader's actions are commonly non-verifiable. This raises the question whether the leader can credibly commit to adopting a certain leadership style because imposing a (dis)utility on the worker is costly to the leader. In fact, in a one-shot interaction, the leader never wants to exercise leadership instruments ex post. However, for the time being, we simply abstract from commitment problems of the leader. In Section 6, we will show that the leader can commit to both leadership styles if the employment relationship is repeated and the leader's discount factor is sufficiently high. Adopting leadership instruments will then be self-enforcing due to the leader's reputational concerns.

The worker is risk neutral and his reservation utility is $\bar{u} \geq 0$. The worker may be protected by limited liability, meaning that his earnings should always be at least equal to a minimum feasible wage level denoted by $\bar{w} \geq 0$. The minimum feasible wage level could be determined by trade union bargaining or minimum wage legislation. ${ }^{3}$ The absence of any exogenous wage restriction can be represented by $\bar{w}=-\infty$ in our model.

Since the leader is assumed to be always willing to induce high effort, the leader's objective is to minimize overall expected costs, which are composed of wage costs (base salary and bonus) and the costs of leadership, to induce high effort.

Our benchmark case is an employment relationship governed by monetary incentives only, i.e., the leader does not implement a leadership style. When the wage constraint $w \geq \bar{w}$ is not binding in the benchmark case, we speak of competitive wage-setting. When the wage constraint is binding, wage-setting is non-competitive. The circumstances under which each of the two situations occurs will be described below.

\section{Analysis}

We start our analysis by examining the benchmark case where the leader does not adopt a leadership style. This setting corresponds to a standard moral-hazard model with binary outcome, binary effort, and limited liability (e.g., Laffont and Martimort, 2002). Next, we investigate whether or not the leader benefits from implementing a given leadership

\footnotetext{
${ }^{3}$ The solution to the model does not change if $\bar{w}$ was negative, in which case the worker could be held liable up to a certain amount of money.
} 
style relative to the benchmark case. This corresponds to a situation where the leader is able to adopt only one style, e.g., because different styles require different personality traits. In Section 5, we study a situation where the leader can choose between a friendly and an unfriendly style.

\subsection{No leadership style}

When the leader uses no leadership style, the only instrument to motivate the worker to exert high effort is the bonus $b$. The worker chooses high effort when his expected utility from doing so is equal to or exceeds the expected utility attained when exerting low effort, or:

$$
w+(\alpha+\rho) b-c \geq w+\alpha b \Leftrightarrow b \geq c / \rho .
$$

In order to attract and retain the worker, the expected utility from accepting and keeping the job must be equal to or exceed the worker's reservation utility:

$$
w+(\alpha+\rho) b-c \geq \bar{u} \Leftrightarrow w \geq \bar{u}-(\alpha+\rho) b+c .
$$

In addition, the worker's base wage cannot be below the minimum level $\bar{w}$ :

$$
w \geq \bar{w}
$$

Hence, the leader minimizes expected wage costs by choosing the lowest bonus that triggers high effort, $b^{*}=c / \rho$, and the lowest base wage that both satisfies the exogenous wage constraint and ensures the participation of the worker:

$$
w^{*}=\max \left\{\bar{w}, \bar{u}-\alpha \frac{c}{\rho}\right\} .
$$

If the minimum wage level $\bar{w}$ is sufficiently small so that the wage constraint is not binding, i.e., $\bar{w} \leq \bar{u}-\alpha \frac{c}{\rho}$, we speak of competitive wage-setting. This is the case in the absence of exogenous wage restrictions $(\bar{w}=-\infty)$ but also if wage restrictions have no bite as workers' outside options are high. By contrast, if $\bar{w}>\bar{u}-\alpha \frac{c}{\rho}$, the wage constraint is binding and we refer to this situation as non-competitive wage-setting. Whether the wage constraint is binding or not does not only depend on the minimum feasible wage and the worker's outside option but also on the worker's preferences and the production technology: The higher the worker's effort costs or the less important high effort for producing high output (i.e., the higher $\alpha / \rho$ ), the more likely the wage constraint is binding.

The total costs for the leader if she does not implement a leadership style, which we 
denote by $C_{0}$, are simply the sum of the base salary and the expected bonus costs:

$$
C_{0}=w^{*}+(\alpha+\rho) b^{*}= \begin{cases}c+\bar{u} & \text { if } \bar{w} \leq \bar{u}-\alpha \frac{c}{\rho} \\ c+\bar{w}+\alpha \frac{c}{\rho} & \text { otherwise }\end{cases}
$$

Hence, with competitive wage-setting, the leader exactly compensates the worker for his cost of effort as well as for missing out on his outside opportunities. By contrast, under non-competitive wage-setting, the leader's costs increase by the difference between the worker's expected wage if he would choose low effort, $\bar{w}+\alpha(c / \rho)$, and his outside option, $\bar{u}$. This cost increase translates into a rent for the worker, which amounts to $\bar{w}-\bar{u}+\alpha(c / \rho)$.

\subsection{Friendly leadership style}

Now suppose the leader can adopt a friendly leadership style that entails a non-monetary benefit $r$ to the worker conditional on good performance at cost $k_{F}$ to the leader. If the leader adopts this style, the worker exerts high effort if:

$$
w+(\alpha+\rho)(b+r)-c \geq w+\alpha(b+r) \Leftrightarrow b \geq(c / \rho)-r .
$$

The worker accepts the job if:

$$
w+(\alpha+\rho)(b+r)-c \geq \bar{u} .
$$

In addition, the worker's base wage cannot be below the minimum level $\bar{w}$. It follows that the optimal bonus is $b_{F}^{*}=(c / \rho)-r$ and the optimal base wage amounts to:

$$
w_{F}^{*}=\max \left\{\bar{w}, \bar{u}-\alpha \frac{c}{\rho}\right\}
$$

Hence, adoption of the friendly leadership style allows the leader to set a lower bonus, namely a reduction of $r$, whereas the optimal base wage does not change relative to the benchmark case without leadership.

The leader's total costs under a friendly leadership style become:

$$
C_{F}=w_{F}^{*}+(\alpha+\rho)\left(b_{F}^{*}+k_{F}\right)= \begin{cases}c+\bar{u}+(\alpha+\rho)\left(k_{F}-r\right) & \text { if } \bar{w} \leq \bar{u}-\alpha \frac{c}{\rho}, \\ c+\bar{w}+\alpha \frac{c}{\rho}+(\alpha+\rho)\left(k_{F}-r\right) & \text { otherwise. }\end{cases}
$$

Comparing $C_{F}$ and $C_{0}$, the total costs with and without adopting the friendly leadership style respectively, it follows that the leader's costs are reduced by adopting this friendly leadership if:

$$
k_{F}-r<0
$$

that is, when the utility gain for the worker is larger than the costs for the leader of 
implementing friendly leadership. Importantly, the cost reduction due to a friendly leadership style is independent of labor market characteristics, the worker's preferences, and the production technology. All benefits from adopting a friendly leadership style accrue to the leader, while the worker's expected utility remains unaffected by friendly leadership: His expected increase in non-monetary utility exactly corresponds to the bonus reduction. In particular, this also implies that friendly leadership is not exploited to reduce the worker's rent under non-competitive wage-setting.

We now ask the question whether the leader's choice is socially optimal. The adoption of a leadership style is socially optimal if it increases the total surplus generated within the leader-worker relationship. We thus need to compare the costs of leadership with the ensued utility for the worker. We have seen that the leadership style also affects wages, but changes in wages leave the total surplus unaffected since they merely constitute a transfer from the leader to the worker. The friendly leadership style increases the worker's expected utility by $(\alpha+\rho) r$ while the leader incurs expected costs $(\alpha+\rho) k_{F}$. It hence is socially optimal to adopt this style if $r>k_{F}$, which is in accordance with the leader's adoption decision.

Proposition 1 summarizes the results for a friendly leadership style.

Proposition 1 Independent of whether the wage constraint binds or not, the leader prefers friendly leadership to no leadership if adopting friendly leadership is socially optimal, i.e., the worker's benefit exceeds the leader's costs $\left(k_{F}<r\right)$. The worker's rent remains unaffected under friendly leadership relative to a situation without leadership.

\subsection{Unfriendly leadership style}

Next consider unfriendly leadership. Under this style, the leader incurs a cost $k_{U}$ to impose a social penalty on the worker after observing poor performance, implying a non-monetary cost of $s$ for the worker. If the leader adopts this style, the worker exerts high effort if:

$$
w+(\alpha+\rho) b-(1-\alpha-\rho) s-c \geq w+\alpha b-(1-\alpha) s \Leftrightarrow b \geq(c / \rho)-s .
$$

The worker accepts the job if:

$$
w+(\alpha+\rho) b-(1-\alpha-\rho) s-c \geq \bar{u}
$$

In addition, the worker's base wage cannot be below $\bar{w}$. The optimal bonus thus is $b_{U}^{*}=(c / \rho)-s$ and the optimal base wage is:

$$
w_{U}^{*}=\max \left\{\bar{w}, \bar{u}-\alpha \frac{c}{\rho}+s\right\}
$$


Accordingly, relative to a situation without leadership, unfriendly leadership allows the firm to lower the bonus by amount $s$. However, the leader might also need to increase the base wage to compensate the worker for the expected cost of the social penalty. This is always the case if unfriendly leadership is implemented under competitive wage-setting $(\bar{w} \leq \bar{u}-\alpha(c / \rho))$. The base wage needed to attract the worker must then increase by amount $s$. This exactly compensates the worker for the reduction in the bonus and the expected costs of the social penalty (which is imposed with probability $1-\alpha-\rho$ ). If unfriendly leadership is implemented under non-competitive wage-setting $(\bar{w}>\bar{u}-$ $\alpha(c / \rho)$ ), the leader only has to increase the base wage if $s$ is so large that the term $\bar{u}-$ $\alpha(c / \rho)+s-\bar{w}$ is positive, in which case the base wage has to be raised by this term. The adoption of unfriendly leadership thus entails an advantageous incentive effect (the bonus can be lowered) as well as a detrimental participation effect (the base wage has to be raised). The latter effect is less pronounced or may even disappear under non-competitive wage-setting because a worker who earns a rent within an employment relationship will not be instantly driven away by the social disutility of unfriendly leadership.

The leader's total costs under unfriendly leadership become:

$$
\begin{aligned}
C_{U} & =w_{U}^{*}+(\alpha+\rho) b_{U}^{*}+(1-\alpha-\rho) k_{U} \\
& = \begin{cases}c+\bar{u}+(1-\alpha-\rho)\left(k_{U}+s\right) & \text { if } \bar{w} \leq \bar{u}-\alpha \frac{c}{\rho}+s, \\
c+\bar{w}+\alpha \frac{c}{\rho}-(\alpha+\rho) s+(1-\alpha-\rho) k_{U} & \text { otherwise. }\end{cases}
\end{aligned}
$$

Hence, comparing $C_{0}$ and $C_{U}$, it follows that when the worker is hired under competitive wage-setting, implementing the unfriendly leadership style increases costs by $(1-\alpha-\rho)\left(k_{U}+s\right)$, and thus is never a good idea. Even though it motivates the worker, it does so by inflicting harm to the worker, for which the leader needs to offer compensation in order to satisfy the participation constraint. The bonus is a better instrument. It motivates and brings an additional benefit to the worker, a benefit that the leader can recoup by reducing the base salary.

However, if the worker is hired under non-competitive wage-setting and hence earns a rent without leadership, the leader does not need to fully compensate the worker for the harm inflicted by unfriendly leadership. Thus, unfriendly leadership may become attractive to the leader. First consider the situation where unfriendly leadership drives the worker's rent down to zero, i.e., $\bar{w} \leq \bar{u}-\alpha(c / \rho)+s$. In this case, the leader benefits from the adoption of this leadership style if:

$$
\begin{aligned}
c+\bar{u}+(1-\alpha-\rho)\left(k_{U}+s\right) & <c+\bar{w}+\alpha \frac{c}{\rho} \\
\Leftrightarrow \bar{u}-\alpha \frac{c}{\rho}+(1-\alpha-\rho)\left(k_{U}+s\right) & <\bar{w} .
\end{aligned}
$$

Thus, the leaders benefits from eliminating the worker's rent through unfriendly leader- 
ship if the minimum feasible wage satisfies:

$$
\bar{u}-\alpha \frac{c}{\rho}+(1-\alpha-\rho)\left(k_{U}+s\right)<\bar{w} \leq \bar{u}-\alpha \frac{c}{\rho}+s .
$$

Such intermediate values of $\bar{w}$ exist if and only if $(1-\alpha-\rho)\left(k_{U}+s\right)<s$, which is equivalent to $k_{U} / s<(\alpha+\rho) /(1-\alpha-\rho)$. Hence, if the cost-benefit ratio of unfriendly leadership is relatively small and $\bar{w}$ takes intermediate values, the leader can profitably adopt an unfriendly leadership style. Now consider the situation where adoption of unfriendly leadership does not eliminate the rent for the worker, i.e., $\bar{w}>\bar{u}-\alpha(c / \rho)+s$. Now unfriendly leadership is beneficial for the leader if:

$$
c+\bar{w}+\alpha \frac{c}{\rho}-(\alpha+\rho) s+(1-\alpha-\rho) k_{U}<c+\bar{w}+\alpha \frac{c}{\rho},
$$

which is again equivalent to $k_{U} / s<(\alpha+\rho) /(1-\alpha-\rho)$.

Overall, from these two cases we can conclude that the leader prefers an unfriendly leadership style to a situation without leadership if and only if the following two conditions are satisfied:

$$
\frac{k_{U}}{s}<\frac{\alpha+\rho}{1-\alpha-\rho} \quad \text { and } \quad \bar{u}-\alpha \frac{c}{\rho}+(1-\alpha-\rho)\left(k_{U}+s\right)<\bar{w} .
$$

The first condition in $(U)$ relates to the incentive effect of unfriendly leadership: The leader can decrease expected bonus costs by $(\alpha+\rho) s$ through incurring expected leadership costs $(1-\alpha-\rho) k_{U}$. Only if the bonus reduction dominates the leadership costs, unfriendly leadership can be profitable. The second condition refers to the participation effect of unfriendly leadership: Only if the worker's rent without leadership, $\bar{w}-\bar{u}+$ $\alpha(c / \rho)$, is sufficiently large, the leader can benefit from adopting an unfriendly leadership style.

The more the penalty harms the worker (the larger $s$ ), the more likely the first condition in $(U)$ holds. However, if $s$ becomes too large, the second condition in $(U)$ will not be satisfied. The firm then has to compensate the worker for unfriendly leadership by a rather high base wage so that this leadership style is not profitable. A high base probability of high output, $\alpha$, unambiguously favors an unfriendly leadership style. The higher $\alpha$, the more likely the bonus reduction takes effect and the less likely the leader has to incur $k_{U}$. In addition, the worker's rent is increasing in $\alpha$. However, the impact of the output-effort sensitivity, $\rho$, is ambiguous. A higher $\rho$ allows the leader to benefit more from the incentive effect but at the same time exacerbates the participation effect. A high output-effort sensitivity means that the worker responds strongly to monetary incentives and hence earns a lower rent.

Given that the cost-benefit ratio of unfriendly leadership is sufficiently small so that the first condition in $(U)$ holds, an unfriendly leadership style is more likely to be adopted the bigger the difference between the minimum feasible wage level $\bar{w}$ and the value of 
the worker's outside option $\bar{u}$. This implies that a worker is more likely to be subject to unfriendly leadership if he is locked in the current employment relationship because his labor market prospects are relatively unattractive. In addition, high effort costs $c$ also favor an unfriendly leadership style. Workers with high effort costs are harder to incentivize by bonuses and therefore earn higher rents.

The worker always suffers from the adoption of an unfriendly leadership style because it always reduces his rent. Moreover, the implementation of unfriendly leadership is never socially desirable because it entails an expected utility loss of $(1-\alpha-\rho) r$ for the worker and expected leadership costs of $(1-\alpha-\rho) k_{U}$. As we have seen, the leader may nevertheless adopt this style under non-competitive wage-setting in order to divert rents from the worker.

The following proposition summarizes our findings for the case of unfriendly leadership

Proposition 2 The leader prefers unfriendly leadership to no leadership if and only if the conditions in $(U)$ hold. Unfriendly leadership is thus implemented only under noncompetitive wage-setting and when the worker's labor market prospects are unattractive (i.e., $\bar{w}-\bar{u}$ is large). Unfriendly leadership lowers the worker's rent relative to the no-leadership benchmark and is socially inefficient.

\section{Optimal choice between leadership styles under non- competitive wage-setting}

The analysis in Section 4 has shown that, with non-competitive wage-setting, leaders may benefit from complementing monetary incentives by both a friendly and an unfriendly leadership style. We now assume that the leader has the skills to implement either style and examine her optimal choice of leadership style, i.e., no leadership style, friendly leadership, or unfriendly leadership. To facilitate the comparison of the two styles, we assume that the leader incurs the same costs for praise and social pressure (i.e., $\left.k_{U}=k_{f} \equiv k\right)$ and the bonus can be reduced by the same amount of money under each style (i.e., $s=r$ ).

From the above analysis it follows that, compared to the absence of a leadership style, the friendly leadership style is profitable if and only if $k / r<1$, while a necessary condition for the unfriendly leadership style to be profitable is that $k / r<(\alpha+\rho) /(1-$ $\alpha-\rho) \equiv \gamma$. Hence, if $k / r \geq \max \{1, \gamma\}$, both leadership styles are too costly relative to their benefits and the worker should be motivated only through monetary incentives.

Now suppose the cost-benefit ratio $k / r$ takes an intermediate value such that $\min \{1, \gamma\}<$ $k / r<\max \{1, \gamma\}$. In this case, at most one leadership style is beneficial. First consider the case $\gamma>1$ or, equivalently, $\alpha+\rho>1 / 2$, implying that a high output is more likely than a low output. Friendly leadership is then not profitable because its cost-benefit 
ratio is too low. Unfriendly leadership, however, has the comparative advantage that leadership costs arise relatively infrequently because the worker is likely to be successful. It is thus profitable if the worker's rent in the absence of leadership, $\bar{w}-\bar{u}+\alpha(c / \rho)$, is sufficiently large, i.e., the second condition in $(U)$ is satisfied. This leads to our next proposition.

Proposition 3 Suppose friendly and unfriendly leadership lead to the same bonus reductions and leadership costs, and the leader can adopt either style. Unfriendly leadership is the only profitable style relative to the benchmark case if and only if

$$
\alpha+\rho>1 / 2 \quad \text { and } \quad(1-\alpha-\rho)(k+r)<\bar{w}-\bar{u}+\alpha(c / \rho) .
$$

The unfriendly leadership style thus dominates the friendly one if the worker is rather productive in the sense that high output is very likely but his labor market prospects are not very attractive (i.e., $\bar{w}-\bar{u}$ is large). In contrast, if $\alpha+\rho<1 / 2$, the leader will always adopt the friendly style.

Finally, if the cost-benefit ratio $k / r$ is so small that $k / r \leq \min \{1, \gamma\}$, the friendly leadership style is always profitable relative to the benchmark. The unfriendly style is also profitable if the second condition in $(U)$ holds. In this case, if the leader is able to adopt both leadership styles at the same time, she should do so. The leader then praises the worker after a good outcome and exerts social pressure after a bad outcome. If it is not feasible to adopt both styles at the same time, the leader may again prefer unfriendly to friendly leadership as the following proposition shows.

Proposition 4 Suppose that $k / r \leq \min \{1, \gamma\}$ and the second condition in $(U)$ holds, implying that both leadership styles are profitable relative to the benchmark case without leadership. Further suppose that the leader cannot adopt both styles at the same time. She will choose the unfriendly leadership style if and only if

$$
\alpha+\rho>1 / 2 \quad \text { and } \quad \bar{w}>\bar{u}-\alpha \frac{c}{\rho}+r+(1-2(\alpha+\rho)) k .
$$

The proof is relegated to the appendix.

Proposition 4 demonstrates that, even if adopting a friendly leadership style is profitable relative to the benchmark, unfriendly leadership can be even more profitable. The first inequality in the proposition states that a necessary condition for unfriendly leadership is that leadership costs arise less frequently than under friendly leadership because high output is rather likely. If, in addition, the worker earns a rent under unfriendly leadership (i.e., $\bar{w}>\bar{u}-\alpha \frac{c}{\rho}+r$ ), the second condition always holds and unfriendly leadership is optimal (note that $1-2(\alpha+\rho)<0$ ). If the worker does not earn a rent under unfriendly leadership, it can still be the optimal leadership style provided that its total costs are below the costs of friendly leadership, which necessarily leads to a rent for the worker. The second inequality states the corresponding condition. Accordingly, 
an unfriendly leadership style is more likely when the costs of leadership, $k$, are high and the benefit of leadership, $r$, is low. In addition, high effort costs trigger unfriendly leadership. Again, unfriendly leadership is also more likely when the worker's labor market prospects are rather unattractive relative to the lowest possible wage payment inside the firm, i.e., $\bar{w}-\bar{u}$ is large.

\section{Self-enforcing leadership}

The previous analysis has abstracted from the leader's problem to commit to adopting a given leadership style. We now address this issue by embedding the employment relationship in a repeated interaction. We assume that the leader needs to hire the worker for an infinite number of periods and has a discount factor $\delta \in(0,1)$. When the leader offers the contract to the worker, she can also announce a leadership style. The worker believes that the leader will implement the announced style as long as the leader complies with her announcement. If the leader reneges on the announcement, the worker believes that she will never again adopt a leadership style. When, after output has been realized, the leader finds it in her best interest to comply with her announcement of a leadership style, we say that the leadership style is self-enforcing.

We first address the question when - given that implementing a given leadership style is worthwhile relative to the benchmark without leadership (i.e., $C_{F}<C_{0}$ or $C_{U}<C_{0}$ )

- the leadership style is also self-enforcing. First consider friendly leadership and assume it is beneficial compared to no leadership, i.e., condition $(F)$ holds and hence $r>k_{F}$. Friendly leadership is self-enforcing if:

$$
k_{F} \leq \sum_{t=1}^{\infty} \delta^{t}\left(C_{0}-C_{F}\right) \quad \Leftrightarrow \quad k_{F} \leq \frac{\delta}{1-\delta}(\alpha+\rho)\left(r-k_{F}\right) .
$$

The condition reflects that the leader will comply with her announcement when her short-term gain from non-compliance, $k_{F}$, does not exceed her long-term loss, the term on the right-hand side. If the leader deviates from her announcement, the worker cannot be motivated by leadership anymore. Hence, the leader can only use monetary incentives to induce high effort, implying that wage costs increase by $C_{0}-C_{F}$ in each future period.

Now consider unfriendly leadership and assume that it is beneficial relative to no leadership, i.e., condition $(U)$ holds. Unfriendly leadership is self-enforcing if:

$$
k_{U} \leq \sum_{t=1}^{\infty} \delta^{t}\left(C_{0}-C_{U}\right)
$$

Inspection of $C_{0}$ and $C_{U}$ shows that the difference between the two wage cost functions depends on whether $\bar{w}>\bar{u}-\alpha(c / \rho)+s$ or not. First assume that this is the case. 
Condition (2) then becomes:

$$
k_{U} \leq \frac{\delta}{1-\delta}\left[(\alpha+\rho) s-(1-\alpha-\rho) k_{U}\right]
$$

If $\bar{w} \leq \bar{u}-\alpha(c / \rho)+s$, condition (2) is equivalent to:

$$
k_{U} \leq \frac{\delta}{1-\delta}\left[\bar{w}+\alpha \frac{c}{\rho}-\bar{u}-(1-\alpha-\rho)\left(k_{U}+s\right)\right]
$$

From conditions (1), (3), and (4) it follows that there is a threshold $\bar{\delta} \in(0,1)$ such that both leadership styles are self-enforcing for all $\delta \geq \bar{\delta}$. Hence, our previous analysis applies for situations with $\delta \geq \bar{\delta}$ where the leader sufficiently cares about future wage costs.

Condition (1) further shows that, whether the friendly leadership style is self-enforcing or not is independent of labor-market conditions as characterized by $\bar{w}$ and $\bar{u}$. By contrast, by (4), whether unfriendly leadership is self-enforcing can be affected by labormarket conditions. If the worker's labor market prospects are rather bad, i.e., $\bar{w}-\bar{u}$ is high, unfriendly leadership is more likely to be self-enforcing.

Finally, the conditions imply that unfriendly leadership may be self-enforcing when friendly leadership is not and vice versa. To compare the self-enforcement properties of the two styles, suppose that $r=s$ and $k_{U}=k_{F}$. Comparison of (1) and (2) shows that, if $C_{U}<C_{F}\left(C_{U}>C_{F}\right)$, there are intermediate values for the discount factor $\delta$ where only the unfriendly (friendly) leadership is self-enforcing. Recall that $C_{U}<C_{F}$ holds if the conditions stated in Proposition 4 are satisfied. Hence, in this situation, unfriendly leadership is self-enforcing for a larger range of discount factors than friendly leadership.

\section{Concluding remarks}

This paper has developed a simple model so as to analyze leaders' choice of leadership style under different wage-setting conditions. We have examined two leadership styles differing in their non-monetary consequences for workers (positive or negative). We have seen that leadership styles that are harmful to workers are only applied when wagesetting is non-competitive. The reason is that, with competitive wage-setting, leaders need to compensate workers for any harm, making incentive pay a superior instrument to motivate workers. However, when wage-setting is non-competitive, full compensation is not needed as workers earn a rent, implying that leaders may use such unfriendly leadership styles, despite them being socially inefficient. Unfriendly leadership in such markets enables the leader to extract rents from the worker. On the other hand, we show that leadership styles that benefit workers are applied whenever they are socially efficient, independent of the wage-setting conditions.

We hope that our analysis will give rise to further theoretical explorations as well 
as to empirical testing of our key predictions. In particular, it would be interesting to see whether there is a link between wage-setting institutions and styles of leadership, as reported by, e.g., employees in questionnaires. Also, one could take our predictions to the lab, creating labor markets with competitive wage-setting and ones with wage floors, seeing whether the choice of leadership styles by participants in the role of leaders are affected by this. Lastly, it would be interesting to further expand the growing evidence base on the causal effects of leadership styles in the field (see Grant and Gino, 2010, Kosfeld and Neckermann, 2011, Kvaløy et al., 2015, Antonakis et al., 2015, Bradler et al., 2016, and Englmaier et al., 2018). According to our theoretical analysis, such studies should also pay attention to employees' willingness to stay with their current employer (as measured by questionnaires or using data on voluntary quits) in addition to their motivation and performance. Our theory predicts that the effects of unfriendly leadership on employee retention are most pronounced in competitive labor markets.

\section{Appendix}

Proof of Proposition 4. Because the second condition in $(U)$ holds, we are in a situation of non-competitive wage-setting. Hence, the leader's costs under friendly leadership are

$$
c+\bar{w}+\alpha(c / \rho)+(\alpha+\rho)(k-r),
$$

while the costs under unfriendly leadership are

$$
\begin{cases}c+\bar{u}+(1-\alpha-\rho)(k+r) & \text { if } \bar{w} \leq \bar{u}-\alpha \frac{c}{\rho}+r \\ c+\bar{w}+\alpha \frac{c}{\rho}-(\alpha+\rho) r+(1-\alpha-\rho) k & \text { otherwise. }\end{cases}
$$

First consider the case $\bar{w} \leq \bar{u}-\alpha \frac{c}{\rho}+r$. Unfriendly leadership then leads to lower costs than friendly leadership iff

$$
\bar{u}-\alpha \frac{c}{\rho}+r+(1-2(\alpha+\rho)) k<\bar{w}
$$

In the current case, such values of $\bar{w}$ exist iff $\alpha+\rho>1 / 2$.

Now consider the case $\bar{w}>\bar{u}-\alpha \frac{c}{\rho}+r$. Unfriendly leadership then entails lower costs than friendly leadership iff $\alpha+\rho>1 / 2$. Hence, combining the results from both cases, unfriendly leadership dominates friendly leadership iff

$$
\alpha+\rho>1 / 2 \quad \text { and } \quad \bar{w}>\bar{u}-\alpha \frac{c}{\rho}+r+(1-2(\alpha+\rho)) k .
$$




\section{References}

[1] Akerlof, George and Rachel Kranton. 2000. "Economics and Identity." Quarterly Journal of Economics, CXV: 715-753.

[2] Akerlof, George and Rachel Kranton. 2005. "Identity and the Economics of Organizations." Journal of Economic Perspectives, 19: 9-32.

[3] Antonakis, John, Giovanna d'Adda, Roberto Weber, Christian Zehnder. 2015. "Just Words? Just Speeches? On The Economic Value of Charismatic Leadership." Mimeo, Insead.

[4] Artz, Benjamin, Amanda H. Goodall, and Andrew J. Oswald. 2018. "How Common Are Bad Bosses?" IZA Discussion Paper No. 11825.

[5] Bass, Bernard M. 1990. "From Transactional to Transformational Leadership: Learning to Share the Vision." Organizational Dynamics, 18: 19-31.

[6] Bénabou, Roland and Jean Tirole. 2003. "Intrinsic and Extrinsic Motivation." Review of Economic Studies, 70: 489-520.

[7] Bénabou, Roland and Jean Tirole. 2006. "Incentives and Prosocial Behavior." American Economic Review, 96: 1652-1678.

[8] Besley, Timothy and Maitreesh Ghatak. 2005. "Competition and Incentives with Motivated Agents." American Economic Review, 95: 616-636.

[9] Besley, Timothy and Maitreesh Ghatak. 2018. "Prosocial Motivation and Incentives." Annual Review of Economics, 10: 411-438.

[10] Bloom, Nicholas, Christos Genakos, Raffaella Sadun and John Van Reenen. 2012. "Management Practises Across Firms and Industries." Academy of Management Perspectives, 26: 12-23.

[11] Bradler, Christiane, Robert Dur, Susanne Neckermann and Arjan Non. 2016. "Employee Recognition and Performance: A Field Experiment." Management Science, 62(11): 3085-3099.

[12] Cassar, Lea, and Stephan Meier. 2018. "Nonmonetary Incentives and the Implications of Work as a Source of Meaning." Journal of Economic Perspectives, 32(3): 215-238.

[13] Clemens, Jeffrey, Lisa B. Kahn, and Jonathan Meer. 2018. "The Minimum Wage, Fringe Benefits, and Worker Welfare." NBER Working Paper No. 24635.

[14] Delfgaauw, Josse and Robert Dur. 2007. "Signaling and Screening of Workers' Motivation." Journal of Economic Behavior \& Organization, 62: 605-624. 
[15] Delfgaauw, Josse and Robert Dur. 2008. "Incentives and Workers' Motivation in the Public Sector." Economic Journal, 118: 171-191.

[16] Dur, Robert, Arjan Non, and Hein Roelfsema. 2010. "Reciprocity and Incentive Pay in the Workplace." Journal of Economic Psychology, 31: 676-686.

[17] Ellingsen, Tore and Magnus Johannesson. 2008. "Pride and Prejudice: The Human Side of Incentive Theory." American Economic Review, 98: 990-1008.

[18] Englmaier, Florian, Stefan Grimm, Dominik Grothe, David Schindler and Simeon Schudy. 2018. "Motivation and Coordination - A Field Experiment on Leadership Functions and Performance in Non-Routine Analytical Team Tasks." Mimeo, University of Munich.

[19] Ferris, Gerald R., Darren C. Treadway, Pamela L. Perrewé, Robyn L. Brouer, Ceasar Douglas, and Sean Lux. 2007. "Political Skill in Organizations." Journal of Management; 33: 290-320.

[20] Grant, Adam and Francesca Gino. 2010. "A little thanks goes a long way: Explaining why gratitude expressions motivate prosocial behavior." Journal of Personality and Social Psychology; 98(6): 946-955.

[21] Hermalin, Benjamin E. 1998. "Toward an Economic Theory of Leadership: Leading by Example." American Economic Review; 88: 1188-1206.

[22] Hermalin, Benjamin E. 2007. "Leading for the Long Term." Journal of Economic Behavior and Organization, 62: 1-19.

[23] Hermalin, Benjamin E. 2017. "At the Helm, Kirk or Spock? Why Even Wholly Rational Actors May Favor and Respond to Charismatic Leaders." Working paper, UC Berkeley.

[24] House, Robert J. 1971. "A Path-Goal Theory of Leadership Effectiveness." Administrative Science Quarterly, 16: 321-338.

[25] House, Robert. J., and Ram. N. Aditya. 1997. "The Social Scientific Study of Leadership: Quo Vadis?" Journal of Management; 23: 409-473.

[26] House, Robert J., Paul J. Hanges, and Mansour Javidan. 2004. Culture, Leadership, and Organizations: The Globe Study of 62 Societies. Sage Publications.

[27] Hyson, Craig Michael. 2016. "Relationship Between Destructive Leadership Behaviors and Employee Turnover." Doctorial study, Walden University.

[28] Judge, Timothy A., Joyce E. Bono, Remus Ilies, and Megan W. Gerhardt. 2002. "Personality and Leadership: A Qualitative and Quantitative Review." Journal of Applied Psychology, 87: 765. 
[29] Komai, Mana and Marc Stegeman. 2010. "Leadership Based on Asymmetric Information." RAND Journal of Economics; 41: 35-63.

[30] Komai, Mana, Marc Stegeman, and Benjamin E. Hermalin. 2007. "Leadership and Information." American Economic Review; 97: 944-947.

[31] Kosfeld, Michael and Susanne Neckermann. 2011. "Getting more work for nothing? Symbolic awards and worker performance." American Economic Journal: Microeconomics; 3: 86-99.

[32] Kvaløy, Ola, Petra Nieken and Anja Schöttner. 2015. "Hidden benefits of reward: A field experiment on motivation and monetary incentives." European Economic Review, 76: 188-199.

[33] Kvaløy, Ola and Anja Schöttner. 2015. "Incentives to Motivate." Journal of Economic Behavior \& Organization, 116: 26-42.

[34] Laffont, J.-J. and D. Martimort. 2002. The Theory of Incentives: The PrincipalAgent Model. Princeton University Press: Princeton and Oxford.

[35] Lazear, Edward. 2012. "Leadership: A Personnel Economics Approach." Labour Economics, 19: 92-101.

[36] Liu, W, DP Lepak, R Takeuchi, HP Sims Jr. 2003. "Matching Leadership Styles with Employment Modes: Strategic Human Resource Management Perspective." Human Resource Management, 13: 127-152.

[37] Lipman-Blumen, J. 2005. The Allure of Toxic Leaders. New York: Oxford University Press.

[38] McGregor, D. 1960. The Human Side of Enterprise. McGraw-Hill, New York, NY.

[39] Pearce, CL , HP Sims Jr, JF Cox, G Ball. 2003. "Transactors, Transformers and Beyond: A Multi-Method Development of a Theoretical Typology of Leadership." Journal of Management Development, 22: 273-307.

[40] Pearson, C. M., L. M. Andersson, and C. L. Porath. 2000. "Assessing and attacking workplace incivility." Organizational Dynamics, 29: 123-137.

[41] Robbins, Stephen P. and Timothy A. Judge. 2013. Organizational Behavior. Global Edition, Pearson Education Limited, Harlow.

[42] Roberts, John. 2004. The Modern Firm: Organizational Design for Performance and Growth. Oxford University Press, Oxford.

[43] Rotemberg, Julio J., and Garth Saloner. 1993. "Leadership Style and Incentives." Management Science, 39: 1299-1318. 
[44] Rotemberg, Julio J., and Garth Saloner. 1994. "Benefits of Narrow Business Strategies." American Economic Review, 84: 1330-1349.

[45] Rotemberg, Julio J., and Garth Saloner. 2000. "Visionaries, Managers, and Strategic Direction." RAND Journal of Economics, 31: 693-716.

[46] Salin, D. (2003). "Bullying and organizational politics in competitive and rapidly changing work environments." International Journal of Management and Decision Making, 4: 35-46.

[47] Tepper, B. (2000). "Consequences of Abusive Supervision." Academy of Management Journal, 42: 100-108.

[48] Van den Steen, Eric J. 2005. "Organizational Beliefs and Managerial Vision." Journal of Law, Economics, and Organization, 21: 256-283.

[49] Zehnder, Christian, Holger Herz, and Jean-Philippe Bonardi. 2017. "A Productive Clash of Cultures: Injecting Economics Into Leadership Research." The Leadership Quarterly, 28: 65-85. 